\title{
EFFECT OF PHYSIOTHERAPY ON SPINAL ALIGNMENT IN CHILDREN WITH POSTURAL DEFECTS
}

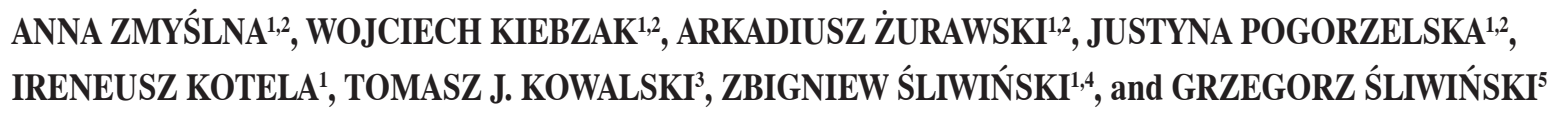

${ }^{1}$ Jan Kochanowski University, Kielce, Poland

Faculty of Medicine and Health Sciences, Institute of Physiotherapy

${ }^{2}$ Provincial Integrated Hospital in Kielce, Kielce, Poland

Świętokrzyskie Center for Pediatrics

${ }^{3}$ Wye Valley Foundation Trust, Hereford, United Kingdom

Department of Orthopaedic Surgery, Hereford County Hospital

${ }^{4}$ Rehabilitation Centre, Zgorzelec, Poland

${ }^{5}$ Technical University in Dresden, Dresden, Germany

Faculty of Electrical and Computer Engineering, Institute of Biomedical Engineering

\begin{abstract}
Objectives: This paper assesses the effect of neurophysiological rehabilitation in children with postural defects on the depth of thoracic kyphosis, lateral spinal deviation and rotation of spinal motor segments. Material and Methods: A total of 201 patients aged 8-15 years old with a postural defect diagnosed by medical examination were enrolled. The analyzed parameters were determined using the DIERS system before the first therapeutic session and after 4 weeks of therapy. The angle of thoracic kyphosis, lateral deviation of the spine and spinal rotation were assessed. The therapy employed techniques associated with the proprioceptive neuromuscular facilitation (PNF) and Vojta's approaches. The results were analyzed separately for both sexes and for patients rehabilitated solely with Vojta's techniques vs. patients rehabilitated according to combined Vojta's and PNF techniques. The $\chi^{2}$ test was used for statistical analyses, at $p<0.05$. Results: There was improvement in the angle of thoracic kyphosis, ranging from 0.14 (among boys with kyphosis $<42^{\circ}$ ) to 5.47 (among girls with kyphosis $\geq 42^{\circ}$ ), spinal rotation, from 0.37 (among boys with kyphosis $\geq 42^{\circ}$ ) to 4.33 (among patients with kyphosis $\geq 42^{\circ}$ rehabilitated solely according to Vojta's method), and lateral deviations, ranging from $1.32 \mathrm{~mm}$ (among boys with kyphosis $<42^{\circ}$ ) to $2.99 \mathrm{~mm}$ (among patients with kyphosis $\geq 42^{\circ}$ rehabilitated solely according to Vojta's method). Conclusions: Neurophysiological rehabilitation of patients with postural defects produced positive effects by improving the angle of thoracic kyphosis, spinal rotation and lateral deviation of the spine. Children with reduced thoracic kyphosis achieved less improvement in the kyphosis angle, lateral spinal deviation and spinal rotation than children with kyphosis $\geq 42^{\circ}$. The DIERS Formetric System enables precise monitoring of therapeutic outcomes. Int J Occup Med Environ Health. 2019;32(1):25-32
\end{abstract}

Key words:

postural defects, PNF, Vojta, DIERS, physiotherapy, rehabilitation

Received: December 19, 2017. Accepted: April 25, 2018.

Corresponding author: Anna Zmyślna, Jan Kochanowski University, Faculty of Medicine and Health Sciences, Institute of Phisiotherapy, al. IX Wieków Kielc 19A, 25-317 Kielce, Poland (e-mail: annwys90@02.pl). 


\section{INTRODUCTION}

Our clinical experience shows that postural defects in the pediatric population may be regarded as a characteristic feature and a health problem of this population [1].

Research on the Polish pediatric population since the 1980s shows decreasing physical performance. The development of civilization and the contemporary lifestyle are also producing a steady increase in the prevalence of postural defects [2]. Reduction in physical activity and repeatedly exceeding the body's energy needs has an adverse effect on the health and posture of the pediatric population [3].

Postural disorders are often produced by poor habits. The maintenance of a particular alignment of the body during daily activities contributes to the development and perpetuation of faulty postures $[4,5]$.

Ignoring postural defects at an early stage of their development may later produce complications in overall health $[6,7]$.

Despite numerous and diverse scientific publications, the etiology of postural defects is not fully elucidated. Epidemiological data also varies, with estimates of prevalence of postural defects ranging from a few to several dozen percent of society [6-8].

Postural defects affect approximately 50-60\% of the Polish pediatric population. They present mostly as habitual faulty postures. The research by the Centre for Health Care Information Technology Systems indicates that a total of 417381 postural defects, mostly of the spine, were diagnosed in Poland in 2007, accounting for $5.19 \%$ of the population aged $0-18$ years old [5].

An important role in the diagnostic process is played by radiographs, which allow for tracing abnormal vertebral morphology and calculating the Cobb angle of spinal curvature. However, radiography involves exposing the patient to ionizing radiation.

At present, precise and non-invasive examinations based on computer technology are becoming increasingly popular. Such methods include moiré topography, the Metrecom System, Integrated Shape Imaging System (ISIS), Posturomet-S, and the DIERS Formetric III 4D system $[1,9]$.

The latter method allows for precise three-dimensional determination of the morphology of the dorsum, orientation of the pelvis and calculation of the spinal mid-line and rotation curves. The optoelectronic technology of the DIERS Formetric III 4D is totally non-invasive and safe for patients, allowing for repeated examinations. It produces very detailed and precise results, enabling a diagnosis that allows for the choice of the best possible and customized therapy [9].

\begin{abstract}
Aim
This paper assesses the effect of neurophysiological rehabilitation in children with postural defects on the depth of thoracic kyphosis, lateral spinal deviation and rotation of spinal motor segments.
\end{abstract}

\section{MATERIAL AND METHODS}

The study enrolled 201 patients undergoing rehabilitation at the Division of Physiotherapy, Świętokrzyskie Center for Pediatrics in Kielce, Poland, who had been diagnosed with a postural defect by medical examination. The participants were aged $8-15$ years old and included 103 boys and 98 girls. History and physical examination did not reveal any comorbidities that could have contributed to the symptoms. The study parameters were assessed before the first therapeutic session and after 4 weeks of therapy.

Inclusion criteria:

- age: 8-15 years old,

- diagnosis of postural defect,

- good overall health ( $\leq 2$ by Eastern Cooperative Oncology Group/World Health Organization [ECOG/ WHO]),

- consent of the legal guardian for the child to participate in the study. 
Exclusion criteria:

- comorbidities that could affect the body axis, such as Scheuermann's disease, genetic conditions such as Beckwith-Wiedemann syndrome, or metabolic disease,

- withdrawal from the study or non-compliance with the instructions regarding the rehabilitation therapy.

The study parameters were assessed with the DIERS Formetric 4D system. Markers were used for improving measurement precision. The DIERS Formetric Average examination was carried out for each patient to assess spinal alignment and vertebral rotation at individual levels. The following parameters were assessed:

- angle of thoracic kyphosis: formed by the apex of thoracic kyphosis and the $\mathrm{C} 7$ and $\mathrm{Th} 12$ spinous processes,

- lateral deviation: distance of the apex of scoliosis from the body's axis of symmetry,

- spinal rotation: differences in skin height overlying the spinal transverse processes.

The study group was divided into 2 subgroups:

- experimental group with reduction of thoracic kyphosis $<42^{\circ}$ (as measured between the C7 and Th12 and the apex of kyphosis), with 55 girls and 69 boys;

- control group with thoracic kyphosis $\geq 42^{\circ}$ (as measured between the $\mathrm{C} 7$ and Th12 and the apex of kyphosis), with 43 girls and 34 boys.

The patients were rehabilitated according to 2 systems. A combination of proprioceptive neuromuscular facilitation (PNF) and Vojta's techniques, with individual therapeutic sessions consisting of a combination of global patterns based on Vojta's method (reflex creeping and the first phase of reflex rolling), a combination of patterns for the limbs and the shoulder and pelvic girdles according to the PNF concept, and patient education regarding the need to assume an optimal body posture for the rehabilitation process. This group comprised a total of 108 patients, including 70 with reduced thoracic kyphosis ( 28 girls and 42 boys) and 38 with kyphosis $\geq 42^{\circ}$ (20 girls and 18 boys).
Vojta's method techniques with individual therapeutic sessions consisted of a combination of global patterns (reflex creeping and the first phase of reflex rolling) and patient education regarding the need to assume an optimal body posture for the rehabilitation process. This group consisted of 93 patients, including 54 with reduced thoracic kyphosis (27 girls and 27 boys) and 39 patients with kyphosis $\geq 42^{\circ}$ ( 23 girls and 16 boys).

The children and their parents received detailed information about the treatment approach and were instructed to practice the exercises at home 3 times daily. Each participant and his or her legal guardians were informed about the methodology of the study and provided their informed consent.

Consent to conduct the study was obtained from the local Ethical Review Board at the Jan Kochanowski University in Kielce, Poland.

The results of the examinations were subjected to a statistical analysis based on the $\chi^{2}$ test, with a threshold of statistical significance at $p<0.05$. The results were analyzed separately for the group rehabilitated according to the PNF and Vojta's approach and the group rehabilitated only according to the Vojta's approach in order to verify the effect of the method of rehabilitation on the results. Results were also compared for boys vs. girls to verify the effect of sex on therapy outcomes.

\section{RESULTS}

The patients rehabilitated according to the PNF and Vojta's approach demonstrated improvement in the angle of thoracic kyphosis amounting to $1.22(\mathrm{p}<0.05)$ among patients with kyphosis $<42^{\circ}$ and 1.23 ( $\mathrm{p}<0.05$ ) among patients with kyphosis $\geq 42^{\circ}$ (Table 1 ). Both subgroups demonstrated a reduction in vertebral rotation: of 1.18 among patients with kyphosis $<42^{\circ}(\mathrm{p}<0.05)$ and 2.13 among patients with kyphosis $\geq 42^{\circ}(\mathrm{p}<0.05)$. Lateral deviation of the spine was reduced by $1.78 \mathrm{~mm}$ among patients with kyphosis $<42^{\circ}(\mathrm{p}<0.05)$ and 


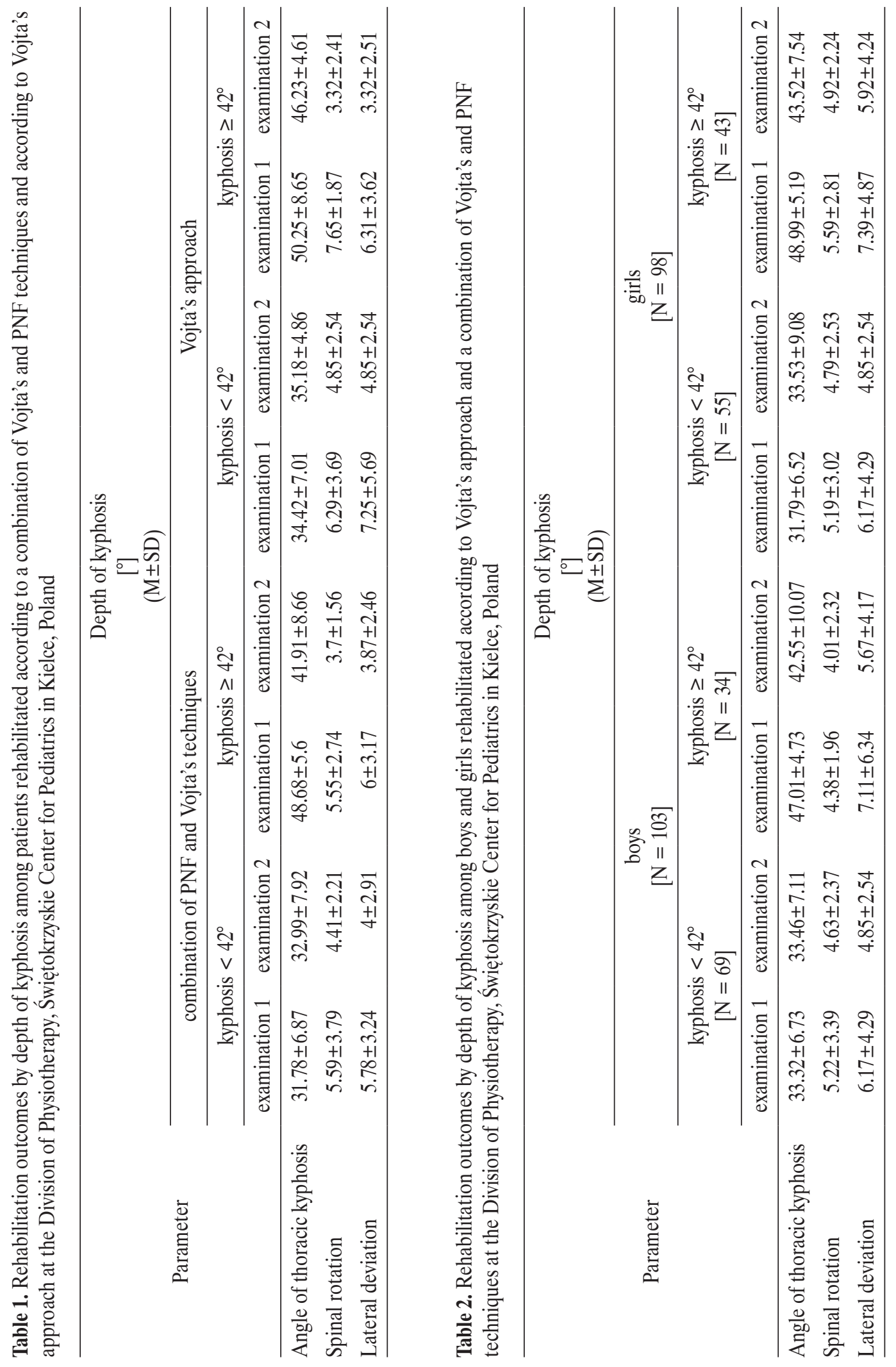


by $2.13 \mathrm{~mm}$ among patients with kyphosis $\geq 42^{\circ}(\mathrm{p}<0.05)$. The patients rehabilitated only according to the Vojta's approach demonstrated improvement in the angle of thoracic kyphosis amounting to $0.76(\mathrm{p}<0.05)$ among patients with kyphosis $<42^{\circ}$ and $4.02(\mathrm{p}<0.05)$ among patients with kyphosis $\geq 42^{\circ}$. Both subgroups demonstrated a reduction in vertebral rotation: of 1.44 among patients with kyphosis $<42^{\circ}(\mathrm{p}<0.05)$ and 4.33 among patients with kyphosis of $\geq 42^{\circ}(p<0.05)$. Lateral deviation of the spine was reduced by $2.4 \mathrm{~mm}$ among patients with kyphosis $<42^{\circ}(\mathrm{p}<0.05)$ and by $2.99 \mathrm{~mm}$ among patients with kyphosis $\geq 42^{\circ}(\mathrm{p}<0.05)$.

Boys demonstrated improvement in the angle of thoracic kyphosis amounting to 0.14 ( $\mathrm{p}>0.05$ ) among patients with kyphosis $<42^{\circ}$ and $4.46(\mathrm{p}<0.05)$ among patients with kyphosis $\geq 42^{\circ}$ (Table 2 ). Both subgroups demonstrated a reduction in vertebral rotation: of 0.59 among patients with kyphosis $<42^{\circ}(\mathrm{p}<0.05)$ and 0.37 among patients with kyphosis $\geq 42^{\circ}(\mathrm{p}>0.05)$. Lateral deviation of the spine was reduced by $1.32 \mathrm{~mm}$ among patients with kyphosis $<42^{\circ}(\mathrm{p}>0.05)$ and by $1.44 \mathrm{~mm}$ among patients with kyphosis $\geq 42^{\circ}(\mathrm{p}<0.05)$. Girls demonstrated improvement in the angle of thoracic kyphosis amounting to $1.74(\mathrm{p}<0.05)$ among patients with kyphosis $<42^{\circ}$ and $5.47(\mathrm{p}<0.05)$ among patients with kyphosis $\geq 42^{\circ}$. Both subgroups demonstrated a reduction in vertebral rotation: of 0.4 among patients with kyphosis $<42^{\circ}(\mathrm{p}<0.05)$ and 0.67 among patients with kyphosis $\geq 42^{\circ}(p<0.05)$. Lateral deviation of the spine was reduced by $1.32 \mathrm{~mm}$ among patients with kyphosis $<42^{\circ}(\mathrm{p}<0.05)$ and by $1.47 \mathrm{~mm}$ among patients with kyphosis $\geq 42^{\circ}(\mathrm{p}<0.05)$.

\section{DISCUSSION}

With the development of civilization, the level of physical activity among children has decreased, eating habits have changed and, most importantly, a sedentary life-style has become dominant. Postural disorders, mostly in the form of reduction of the natural curvatures of the spine, are being observed more and more frequently among children. Such abnormal postural patterns lead to disorders associated with non-physiological loading of the spine and spinal joints. The dorsum with attenuated curvatures is more prone to developing abnormal curvatures in the frontal plane. Early detection of postural defects could contribute to effective prevention and treatment. It is extremely difficult to obtain an effective and objective attitude assessment both for diagnostic purposes and for monitoring the rehabilitation process [10].

The research regarding the causes of abnormal postures among children has been conducted for many years, but an unambiguous explanation is yet to be provided. Children with scoliosis have been found to demonstrate more pronounced problems with body balance, reduced response to stimuli and prolonged baseline position recovery time. Abnormal lateral spinal curvatures are particularly dangerous among postural defects; hence, the importance of early diagnosis [3].

The DIERS Formetric system is a non-invasive and objective imaging technique that may be used for assessing body posture. Both static and dynamic postural imaging may be performed and it may also be used for assessing treatment outcomes. The DIERS system was chosen for this study also in view of the short duration of the examination, low cost and the possibility of an unlimited number of repetitions [11].

According to the 2016 study, the DIERS Formetric 4D system allows for objective assessment of the outcomes of on-going rehabilitation for patients with scoliosis [11].

The determination of a normal range for the angle of thoracic kyphosis has been a problem for researchers for years. The Scoliosis Research Society has defined this range in the developing adolescent as $20-40^{\circ}$ [12-14]. In a study of 316 healthy individuals aged 2-27 years old, Wenger and Frick [14] found that the upper limit of the normal range for thoracic kyphosis was 45. It was noted 
that average kyphosis increased with age, from 20 in childhood to 25 among teenagers to 40 in adults [14].

For the purposes of our study, the limit of the physiological range of thoracic kyphosis was assumed at $42^{\circ}$ in accordance with the protocol of the DIERS-based examination and guidelines [16].

The lack of consistent definition of kyphosis in literature makes it difficult to compare different studies since the inclusion criteria may vary, making it virtually impossible to distinguish the upper normal range of normal kyphosis and severe juvenile deformity [17].

The problem of pronounced thoracic kyphosis merits further studies because a sedentary life-style contributes to loss of the lumbar lordosis, further accentuation of kyphosis and an increase in the prevalence of postural defects in young people [18].

As it has been demonstrated, restoration of physiological lumbar lordosis and thoracic kyphosis stabilizes the spine with regard to lateral deformity by improving spinal alignment in the frontal plane. This is confirmed by the research presented in this article [19].

Sagittal spinal misalignment is also a significant contributor to pain, which is often chronic [20,21].

According to the Society on Scoliosis Orthopedic and Rehabilitation Treatment (SOSORT), postural control is the most important determinant of body axis improvement. Members of the SOSORT also consider that therapy must necessarily include elements of elongation and proprioceptive stimulation. The beneficial effect on therapy of exercise tasks that may be easily performed in the home setting is also underlined. Patients should perform such exercises on their own for approximately $20 \mathrm{~min} /$ day. These recommendations were reflected in our choice of the methods of treatment in the experimental group, and they produce a positive effect in therapy [22].

The choice of the therapeutic approach is of key importance for the final outcome. For this study, we used a combination of neurophysiological approaches (Vojta's one and PNF), which resulted in improvement in the body axis in all 3 planes. Similar results have also been obtained by other researchers utilizing these methods, which indicates that they are useful in the treatment of individuals with postural defects [23].

Statistically significant improvement in the body axis was obtained in both groups investigated, which leads to the conclusion that the customization of therapy for individual patients and patient education are more important for a positive therapeutic outcome than the specific method employed [24].

\section{CONCLUSIONS}

Neurophysiological rehabilitation of patients with postural defects produced positive effects by improving the angle of thoracic kyphosis, spinal rotation and lateral deviation of the spine.

Children with reduced thoracic kyphosis achieved less improvement in the kyphosis angle, lateral spinal deviation and spinal rotation than children with kyphosis $\geq 42^{\circ}$.

The DIERS Formetric System enables precise monitoring of therapeutic outcomes.

\section{REFERENCES}

1. Rosa K, Muszkieta R, Zukow W, Napierała M, Cieślicka M. [The incidence of defects posture in children from classes I to III elementary school]. J Health Sci. 2013;3(12):107-36. Polish.

2. Janiszewska R, Tuzinek S, Nowak S, Ratyńska A, Biniaszewski T. [Abnormalities of posture in 6-12 year-old children Pupils of primary schools from Radom - A pilot study]. Probl Hig Epidemiol. 2009;90(3):342-6. Polish.

3. Perriman DM, Scarvell JM, Hughes AR, Lueck CJ, Dear KB, Smith PN. Thoracic hyperkyphosis: A survey of Australian physiotherapists. Physiother Res Int. 2012;17(3):167-78, https://doi.org/10.1002/pri.529.

4. Górecki A, Kiwerski J, Kowalski J, Marczyński W, Nowotny J, Rybicka M. [Prophylactics of postural deformities in children and 
youth carried out within the teaching environment - Experts recommendations]. Pol Ann Med. 2009;16(1):168-77. Polish.

5. Wilczyński J. [The most common faulty postures among boys aged 13-16 years measured by moiré's photogrammetric method]. Med Pr. 2006;57(4):347-52. Polish.

6. Maciałczyk-Paprocka K, Krzyżaniak A, Kotwicki T, Kałużny $€$, Przybylski J. [The body posture of preschool children]. Probl Hig Epidemiol. 2011;92(2):286-90. Polish.

7. Maciałczyk-Paprocka K, Krzyżaniak A, Kotwicki T, Sowińska A, Stawińska-Witoszyńska B, Krzywińska-Wiewiorowska M, et al. [Postural defects in primary school students in Poznań]. Probl Hig Epidemiol. 2012;93(2):309-14. Polish.

8. Paprocki M, Rychter P, Wilczyński J. [Accuracy of the optoelectronic test body posture Formetric Diers Method III 4D in comparison with the result of the X-ray pictures]. J Edu Health Sport. 2016;6(4):385-98, https://doi.org/10.5281/zenodo.50535. Polish.

9. Massimiliano M, Raimondi P, Paoloni M, Pellanera S, Di Michele A, Di Renzo S, et al. Vertebral rotation in adolescent idiopathic scoliosis calculated by radiograph and back surface analysis-based methods: Correlation between the Raimondi method and rasterstereography. Eur Spine J. 2013; 22(2):367-71, https://doi.org/10.1007/s00586-012-2564-9.

10. Tribus CB. Scheuermann's kyphosis in adolescents and adults: Diagnosis and management. J Am Acad Orthop Surg. 1998;6(1):36-43, https://doi.org/10.5435/00124635-199 801000-00004.

11. Książek-Czekaj A, Wiecheć M, Śliwiński G, Śliwiński Z. Monitoring of scoliosis improvement results using the DIERS system. Fizjoter Pol. 2016;16(3):124-34.

12. Wenger DR. Roundback. The art and practice of children's orthopaedics. New York: Raven Press, Ltd; 1993. p. 422-54.

13. Lowe TG. Scheuermann disease. J Bone Joint Surg Am. 1990;72(6):940-5, https://doi.org/10.2106/00004623-199072 060-00026.

14. Wenger DR, Frick SL. Scheuermann kyphosis. Spine. 1999;24(24):2630-9, https://doi.org/10.1097/00007632-19991 2150-00010.
15. Weiss HR, Turnbull D, Bohr S. Brace treatment for patients with Scheuermann's disease - A review of the literature and first experiences with a new brace design. Scoliosis. 2009;4:22, https://doi.org/10.1186/1748-7161-4-22.

16. Harzmann HCh. The value of the video scanning stereogram as a screening method of scoliosis and structural scoliosis [dissertation]. München: Ludwig-Maximilians-University, Faculty of Medicine; 2000.

17. Weiss HR, Werkmann M. Treatment of chronic low back pain in patients with spinal deformities using a sagittal re-alignment brace. Scoliosis. 2009;4:7, https://doi.org/10.1186/17487161-4-7.

18. Van Loon PJ, Kühbauch BA, Thunnissen FB. Forced lordosis on the thoracolumbar junction can correct coronal plane deformity in adolescents with double major curve pattern idiopathic scoliosis. Spine. 2008;33(7):797-801, https://doi. org/10.1097/BRS.0b013e3181694ff5.

19. Weiss HR, Werkmann M. Unspecific chronic low back pain A simple functional classification tested in a case series of patients with spinal deformities. Scoliosis. 2009;4:4, https:// doi.org/10.1186/1748-7161-4-4.

20. Weiss HR, Turnbull D. Physical and technical rehabilitation of patients with Scheuermann's disease and kyphosis. In: Stone JH, Blouin M, editors. International encyclopedia of rehabilitation [Internet]. Buffalo: CIRRIE; 2010 [cited 2017 Nov 19]. Available from: https://gradebuddy. com/doc/260544/physical-and-technical-rehabilitation-ofpatients-with-scheuermanns-disease-and-kyphosis.

21. De Mauroy J, Weiss H, Aulisa A, Aulisa L, Brox J, Durmala J, et al. 7th SOSORT consensus paper: Conservative treatment of idiopathic and Scheuermann's kyphosis. Scoliosis Spinal Disord. 2010;5:9, https://doi.org/10.1186/17487161-5-9.

22. Lee BK. Influence of the proprioceptive neuromuscular facilitation exercise programs on idiopathic scoliosis patient in the early 20s in terms of curves and balancing abilities: Single case study. J Exerc Rehabil. 2016;12(6):567-74, https:// doi.org/10.12965/jer.1632796.398. 
23. Steffan K. [Physical therapy for idiopathic scoliosis]. Orthopade. 2015;44(11):852-8, https://doi.org/10.1007/s00132015-3174-0. German.

24. Berdishevsky H, Lebel VA, Bettany-Saltikov J, Rigo M, Lebel A, Hennes A, et al. Physiotherapy scoliosis-specific exercises - A comprehensive review of 7 major schools. Scoliosis Spinal Disord. 2016;11:20, https://doi.org/10.1186/ s13013-016-0076-9.

This work is available in Open Access model and licensed under a Creative Commons Attribution-NonCommercial 3.0 Poland License - http://creativecommons.org/ licenses/by-nc/3.0/pl/deed.en. 